\title{
Analysis I
}

\section{By Einar Hille, Yale University}

This volume deals with functions of one variable, real or complex. Complex numbers and functions of one variable are introduced at an early stage.

Spring, 1964

672 pages. $\$ 10.00$

\section{A Course in Mathematical Analysis, Volumes I and II}

By Norman B. HaAser, University of Notre Dame, Joseph P. LaSAlle, Research Institute for Advanced Study, Baltimore, Joseph A. Sulurvan, Boston College

These two volumes present elementary analysis both as mathematics and as an instrument of science in the spirit of contemporary mathematics.

Volume I. 1959

719 pages. $\$ 8.75$

Volume II. Spring, 1964

704 pages. $\$ 10.50$

\section{Differential Equations}

By Shepley Ross, University of New Hampshire

This introduction to differential equations discusses basic methods, theory, and applications.

Spring, 1964

300 pages. $\$ 6.50$

\section{BLAISDELL PUBLISHING COMPANY}

A Division of Ginn and Company

501 Madison Avenue

New York, New York 10022 


\section{Journals Published by the \\ American Mathematical Society}

\section{Soviet Mathematics-Doklady}

Soviet MAThEMATICS-DOKLADY is a translation journal containing the entire pure mathematics section of the DoKLADY AKADEMII NAUK SSSR, the Reports of the Academy of Sciences of the USSR. The DokLADY for a year contains more than 500 articles, each about 4 pages long. Issued bimonthly in January, March, May, July, September, and November.

Subscriptions, $\$ 35.00$.

Single issues are $\$ 7.00$. Vols. $1,2,3$, and 4 (1960-1963), price per volume $\$ 40.00$.

\section{Mathematical Reviews}

This journal is devoted to abstracts and reviews of the current mathematical literature of the world. Two volumes of MATHEMATICAL REVIEWS will be published in 1964, Volume 27 and Volume 28. Each volume will consist of 6 regular issues plus an index issue. In each regular issue the abstracts and reviews are grouped under subject headings. Publication began in 1940. Subscription price per volume of 7 issues is $\$ 50.00 ; 2$ volumes per year $\$ 100.00$.

Prior to 1961 it appeared in eleven single issues. Orders for complete volumes only are accepted. Volumes 1-24 are available at the following prices: Vols. 1-16 (1940$1955)$, $\$ 42.00$ each; all other volumes $\$ 50.00$.

\section{Notices of the American Mathematical Society}

This journal announces the programs of the meetings of the Society. It carries the abstracts of all contributed papers presented at the meetings of the Society and publishes news items of interest to mathematical scientists.

The subscription price is $\$ 7.00$ per annual volume of seven numbers. A single copy is $\$ 2.00$. Orders for back volumes (back issues of the last two years only are available) are $\$ 14.00$ per volume.

All communications should be addressed to the Editor, 190 Hope Street, Providence, Rhode Island 02906. News items and insertions for each issue must be in the hands of the editor on or before the deadline for the abstracts for the papers to be presented in the meetings announced in that issue. These deadlines are published regularly on the back of the title page.

\section{Mathematics of Computation}

A journal devoted to original papers in numerical analysis, the application of numerical methods and high-speed calculator devices, the computation of mathematical tables, the theory of high-speed calculating devices and other aids to computation. In addition it publishes reviews and notes in these and related fields. Published by the Society for the National Academy of Sciences-National Research Council.

The subscription price is $\$ 8.00$ per volume of 4 issues. Single copies are $\$ 2.50$. Back issues insofar as they are available: $(1943-1962) \$ 3.00$ per issue; $\$ 12.00$ per volume. Write for specific information concerning availability.

\section{Chinese Mathematics-Acta}

This is a cover-to-cover translation into English of Acta Mathematica Sinica published by Academia Sinica Peking, People's Republic of China. Acta Mathematica Sinica contains current research in all fields of pure mathematics. Subscription price per volume $\$ 20.00$.

Volume 1, 1962 of the translation (corresponding to Volume 10, 1960 of the original) contained three issues. Volume 2, 1963 (Volume 11, 1961) and Volume 3, 1963 (Volume 12, 1962 of the original) will have four issues. In each case the translation will have the same number of issues as the original.

Back volumes $\$ 30.00$; single issue price one third of the volume price. 


\section{Journals Published by the}

\section{American Mathematical Society}

\section{Bulletin of the American Mathematical Society}

This journal is the official organ of the Society. It reports official acts of the Society and the details of its meetings. It contains some of the officially invited addresses presented before the Society, reviews of advanced mathematical books, research problems and a department of research announcements.

The subscription price is $\$ 7.00$ per annual volume of six numbers.

Research Problems and Invited Addresses offered for publication should be sent to Walter Rudin, Department of Mathematics, University of Wisconsin, Madison, Wisconsin; Book Reviews to Felrx Browder, School of Mathematics, Institute for Advanced Study, Princeton, New Jersey. Research Announcements offered for publication should be sent to some member of the Council of the Society, and communicated by him to E. H. Spanier, Department of Mathematics, University of California, Berkeley 4, California. All other communications to the editors should be sent to the Managing Editor, FeLIX BROwDER.

The members of the Council for 1964 are: A. A. Albert, H. A. Antosiewicz, Lipman Bers, Felix Browder, R. C. Buck, Eugenio Calabi, S. S. Chern, P. E. Conner, C. W. Curtis, M. L. Curtis, D. A. Darling, J. L. Doob, G. F. D. Duff, Eldon Dyer, J.W. Green, P. R. Halmos, G. A. Hedlund, M. H. Heins, L. A. Henkin, Edwin Hewitt, A. S. Householder, G. A. Hunt, Nathan Jacobson, Fritz John, V. L. Klee, P. D. Lax, M. M. Loève, R. C. Lyndon, G. W. Mackey, Lawrence Markus, W. S. Massey, A. E. Meder, Jr., J. W. Milnor, G. D. Mostow, Louis Nirenberg, R. S. Pierce, Everett Pitcher, Alex Rosenberg, Walter Rudin, Seymour Sherman, I. M. Singer, E. H. Spanier, J. D. Swift, Michio Suzuki, A. E. Taylor, J. V. Wehausen, John Wermer, George Whaples, Daniel Zelinsky, Leo Zippin, Antoni Zygmund.

\section{Proceedings of the American Mathematical Society}

This journal is devoted entirely to research in pure and applied mathematics and is devoted principally to the publication of original papers of moderate length. A department called Shorter Notes was established for the purpose of publishing very short papers of an unusually elegant and polished character, for which there is normally no other outlet.

The subscription price is $\$ 11.00$ per annual volume of six numbers.

Papers in algebra and number theory should be sent to Alex Rosenberg, Department of Mathematics, Cornell University, Ithaca, New York or George WhaPLES, Department of Mathematics, Indiana University, Bloomington, Indiana; in probability, real variables, logic, and foundations to R. C. Buck, Department of Mathematics, University of Wisconsin, Madison 6, Wisconsin; in abstract analysis to either R. C. Buck or Alex Rosenberg; in geometry and topology to Eldon Dyer, Eckhart Hall, University of Chicago, Chicago 37, Illinois; in other branches of analysis, applied mathematics, and all other fields to M. H. HeINs, Department of Mathematics, University of Illinois, Urbana, Illlinois, or FrITZ JoHN, Courant Institute of Mathematical Sciences, 4 Washington Place, New York 3, New York. All other communications to the editors should be addressed to the Managing Editor, ELDON DYER.

\section{Transactions of the American Mathematical Society}

This journal is devoted entirely to research in pure and applied mathematics, and includes in general longer papers than the PROCEEDINGS.

Four volumes of three numbers each will be published in 1964. The subscription price is $\$ 8.00$ per volume.

Papers in analysis and applied mathematics should be sent to LIPMAN BERS, Courant Institute of Mathematical Sciences, New York University, New York 3, New York; in topology to W. S. MAsSEY, Department of Mathematics, Yale University, Box 2155, Yale Station, New Haven, Connecticut; in algebra, number theory, and logic to Daniel Zelinsky, Department of Mathematics, Northwestern University, Evanston, Illinois; in geometry and abstract analysis to I. M. Singer, Department of Mathematics, Massachusetts Institute of Technology, Cambridge 39, Massachusetts; in statistics and probability to MicheL LOÈve, Department of Statistics, University of California, Berkeley 4, California. All other communications to the editors should be addressed to the Managing Editor, DANIEL ZELINSKY. 


\section{CONTENTS-Continued from back cover}

S. Schanuel. On heights in number fields . . . . . . . . . . 262

Stanley Kaplan. Differential equations in which the Poisson process plays a role....................... . 264

C. T. C. Wall. An obstruction to finiteness of CW-complexes. 269

D. T. Haimo. Variation diminishing transformations..... 271

L. Carlitz. A problem in partitions related to the Stirling

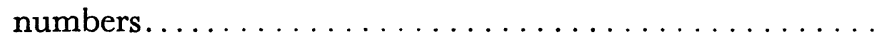

Wilhelm Klingenberg. On the number of closed geodesics on a Riemannian manifold....................... 279

Gilbert Baumslag and Arthur Steinberg. Residual nilpotence and relations in free groups....................

Edwin Duda. A locally compact separable metric space is almost invariant under a closed mapping. ............

Melvin Henriksen and J. R. Isbell. Averages of continuous functions on countable spaces.

A. M. Krall. On the real parts of zeros of exponential polynomials.

M. Arkowitz and C. R. Curjel. The group of homotopy equivalences of a space........... . . . . . . . . . . . 293

W. V. Quine and Hao Wang. On ordinals. . . . . . . . . . 297

F. E. Browder. Nonlinear elliptic problems. II . . . . . . . . 299

Daihachiro Sato and E. G. Straus. Rate of growth of Hurwitz entire functions and integer valued entire functions..... 303

Marvin Marcus and Henryk Minc. Inequalities for general matrix functions........................ 308

R. W. Beals. A note on the adjoint of a perturbed operator. . 314

Shmuel Kantorovitz. Classification of operators by means of the operational calculus.................... 316

Walter Rudin. Essential boundary points. . . . . . . . . 321

Takashi Ono. On the relative theory of Tamagawa numbers. 325

Erratum, Volume $69 \ldots \ldots \ldots \ldots \ldots \ldots \ldots \ldots \ldots \ldots \ldots . \ldots 27$ 


\section{CONTENTS \\ March, 1964}

\section{Invited Addresses}

J.-P. Kahane. Lacunary Taylor and Fourier series....... . 199

Louis de Branges. New and old problems for entire functions. 214

\section{Book Reviews}

A. Rényi. Wahrscheinlichkeitsrechnung mit einem Anhang über Informations theorie. Reviewed by Kai Lai Chung.

Serge Lang. Introduction to differentiable manifolds. Reviewed by Ralph Abraham....................

S. Helgason. Differential geometry and symmetric spaces. Reviewed by Louis Auslander. . . . . . . . . . . . . . . . . 227

Walter Rudin. Fourier analysis on groups. Reviewed by J.-P. Kahane ............................

Shoshichi Kobayashi and Katsumi Nomizu. Foundations of differential geometry. Reviewed by Robert Hermann....

R. H. Crowell and R. H. Fox. Introduction to knot theory. Reviewed by Lee P. Neuwirth................... . 235

The November Meeting in Atlanta....................... 239

The November Meeting in Pasadena................... 240

The November Meeting in Madison . . . . . . . . . . . . . . 242

\section{Research Announcements}

J. J. Schäffer. On Floquet's theorem in Hilbert spaces.... . 243

Yoshindo Suzuki. A complete classification of the $\Delta_{2}^{1}$-functions.............................. 246

Donald Babbitt. The Wiener integral and perturbation theory of the Schrödinger operator. . . . . . . . . . . . 254

J.-P. Kahane and R. Salem. Distribution modulo 1 and sets of uniqueness............................... 259

Continued on inside back cover (FEORGE BANTA COMPANY, INC., MENASHA, WISCONSIN 